\section{Experiências de pais de crianças nascidas com microcefalia, no contexto da epidemia de Zika, a partir da comunicação do diagnóstico}

\author{
Experiences of parents of children born with \\ microcephaly during the Zika epidemic following \\ disclosure of the diagnosis
}

\section{Experiencias de padres de niños nacidos con microcefalia en el contexto de la epidemia de Zika a partir de la comunicación del diagnóstico}

\section{Resumo}

Este artigo tem como objetivo compreender como os pais de crianças com microcefalia receberam a comunicação do diagnóstico. Trata-se de um estudo qualitativo, realizado no Centro de Referência Estadual em Neurodesenvolvimento, Assistência e Reabilitação de Crianças (NINAR), em São Luís, Maranhão, Brasil, no período de abril de 2017 a fevereiro de 2018. Participaram do estudo os responsáveis de crianças com microcefalia. As técnicas de coleta de dados foram entrevistas estruturadas e semiestruturadas com 3 casais, 16 mães e 1 bisavó, totalizando 20 entrevistas. A amostra foi definida pelo critério de saturação, e foi realizada análise de conteúdo na modalidade temática. Para 18 entrevistados, a forma da comunicação foi considerada inadequada e traumática, algumas vezes atrelada ao sentido de "fim da vida" e dissociada de orientações sobre as formas de enfrentar a situação e cuidar do filho. Em 15 dos 20 casos, o diagnóstico de microcefalia foi dado por médicos e, em 3 casos, por enfermeira, por sogra (que soube pelo médico) e por uma funcionária da Secretaria de Saúde. Os dois outros não receberam diagnóstico: um casal soube da microcefalia pela Declaração de Nascido Vivo e outro associou o problema do filho a informações veiculadas na mídia. Foram três os eixos temáticos analisados: omissão do diagnóstico, processo de comunicação do diagnóstico e antecipação de prognóstico. As formas de comunicação do diagnóstico da microcefalia aos familiares influenciaram nos modos de aceitação e enfrentamento da situação.

Comunicação; Família; Pais; Microcefalia; Zika Vírus
Poliana Soares de Oliveira 1

Zeni Carvalho Lamy 1

Carolina Nívea Moreira Guimarães 1

Camila Brito Rodrigues 1

Antonio Augusto Moura da Silva 1

Vanda Maria Ferreira Simões 1

Patrícia da Silva Sousa 2

doi: 10.1590/0102-311X00226618

\section{Correspondência}

P. S. Oliveira

Rua Raimundo Correia 376, São Luís,

MA 65031-510, Brasil.

poliana_soaresoliveira@hotmail.com

1 Universidade Federal do Maranhão, São Luís, Brasil. 2 Centro de Referência Estadual em Neurodesenvolvimento, Assistência e Reabilitação de Crianças, São Luís, Brasil. 


\section{Introdução}

Em 2015, a epidemia do Zika vírus causou um cenário de emergência sanitária no Brasil 1, quando ocorreu um crescimento considerável na quantidade de crianças nascidas com microcefalia, em alguns casos revelada ainda na vida intrauterina 2. Observou-se que os afetados apresentavam alterações radiológicas peculiares e achados que iam além da microcefalia, tendo-se descartado as principais causas de infecção congênita, bem como as causas genéticas e ambientais 3 .

As investigações clínicas desse surto evidenciaram a associação com a infecção pelo Zika vírus que, ao acometer mulheres durante a gestação, causa, nas crianças, a síndrome congênita pelo Zika vírus (SCZ) 2.

A síndrome congênita associada à infecção pelo Zika vírus compreende um conjunto de sinais e sintomas que variam de alterações físicas a desordens neurológicas, incluindo alterações oculares, auditivas, desproporção craniofacial, deformidades articulares e de membros, irritabilidade e convulsões, entre outras consequências, destacando-se a microcefalia 2 , definida como perímetro cefálico abaixo de dois desvios padrões para idade e sexo, de acordo com a curva de referência Intergrowth-214.

A microcefalia está associada a atrasos no desenvolvimento motor, cognitivo e também de outras funções do organismo, nos mais variados graus de comprometimento do sistema nervoso central, implicando baixa qualidade e expectativa de vida 5,6 .

No Brasil, a microcefalia já era endêmica, por fazer parte do quadro clínico de várias infecções congênitas e alterações genéticas conhecidas mas, com a ocorrência dos casos de infecção pelo Zika vírus, ganhou status de epidemia e passou a ter grande visibilidade nos noticiários brasileiros 2,7.

Essa superexposição midiática da microcefalia evidenciou o quanto, até então, o assunto era silenciado e trouxe à tona a situação de outras crianças com deficiências. Entretanto, a necessidade de resposta e priorização das ações governamentais, em caráter emergencial, para as crianças afetadas pelo Zika vírus, reforçou, em outros momentos, a invisibilidade dessas outras condições crônicas, para as quais não existiam programas específicos de atendimento 1,8,9.

As frequentes notícias em todas as mídias comoveram a população, angustiaram casais que aguardavam o nascimento de seus filhos e mesmo aqueles que ainda planejavam uma gestação, tendo em vista que esse cenário modificava o imaginário das pessoas com relação às expectativas para o nascimento de uma criança 2,7,10.

O nascimento de um filho com alguma condição crônica de saúde leva os pais a enfrentarem a crise da perda do filho perfeito e à necessidade de se ajustarem às novas demandas de cuidado ${ }^{11}$.

Durante a gestação e, por vezes, muito antes, o casal constrói uma imagem do filho que está por vir. Essa imagem do bebê ideal é proveniente de suas próprias identificações, aspirações e experiências 12 . Com a chegada do bebê real, exacerba-se a distância entre o filho imaginado e o que havia sido projetado para ele, o que modifica expectativas e planos, que precisam ser refeitos à luz da nova realidade 13 .

No caso do filho que nasce com a SCZ, além de todas essas questões já conhecidas, sobrepõem-se a intensa exposição midiática e as incertezas, por se tratar de uma doença nova para a qual ainda não há muitas respostas.

Esse processo de adaptação e aceitação do filho real pode ter início no momento da comunicação do diagnóstico. A forma como é transmitida a notícia da deficiência do filho pode ter influência decisiva nas reações dos pais 14 .

Transmitir notícias difíceis é um processo complexo em qualquer situação, sendo ainda mais difícil quando envolve expectativas relacionadas a gestação, parto e nascimento de uma criança 15 .

Uma comunicação do diagnóstico realizada de forma inadequada pode deixar o casal confuso, o que influencia negativamente no processo de aceitação do filho 16. Ao contrário, a comunicação eficaz com esclarecimento de dúvidas, orientações e apoio psicológico ajuda na compreensão, aceitação e adaptação à nova situação. A partir da comunicação do diagnóstico para a família é que o bebê vai sendo construído no imaginário dos pais 17,18.

Em geral, as equipes de saúde não são preparadas para a comunicação de notícias difíceis, não conhecem os protocolos disponíveis que podem oferecer ferramentas para uma abordagem adequada 14 e, especialmente, no início dessa nova epidemia, não contavam com todas as informações necessárias para ofertar apoio e segurança às famílias. 
Portanto, no contexto da epidemia do Zika vírus, a comunicação do diagnóstico de microcefalia à família representou um momento de grande impacto. Essa pesquisa teve como objetivo compreender como os pais de crianças com microcefalia receberam a comunicação do diagnóstico.

\section{Metodologia}

Trata-se de uma pesquisa exploratória de abordagem qualitativa, parte do estudo Síndrome Congênita pelo Zika Vírus, Soroprevalência e Análise Espacial e Temporal de Zika Vírus e Chikungunya no Maranhão. O estudo foi realizado no período de abril de 2017 a fevereiro de 2018, na cidade de São Luís (Maranhão), no Centro de Referência Estadual em Neurodesenvolvimento, Assistência e Reabilitação de Crianças (NINAR).

Foram incluídos familiares responsáveis por crianças com microcefalia presumível pelo Zika vírus, com alterações na tomografia cerebral e fenótipo característicos da doença e em acompanhamento no local da pesquisa.

$\mathrm{Na}$ ocasião, estavam cadastradas 146 crianças. Para escolha dos entrevistados, foram utilizadas duas estratégias: realização de um quadro com características dos familiares e crianças e consulta a um informante-chave. Buscou-se contemplar a diversidade das situações encontradas, a partir da gravidade do quadro clínico da criança, da situação conjugal, da idade dos pais, do número de filhos, da escolaridade, da renda e do local de residência. Foram entrevistadas vinte famílias. A definição do número de entrevistas se deu no campo, de acordo com o critério de saturação.

A técnica utilizada para a coleta de dados foi entrevista semiestruturada. Para isso, foram elaborados dois instrumentos. O primeiro, um questionário estruturado com dados de identificação da criança, características socioeconômicas e demográficas, antecedentes maternos e paternos, dados relacionados a gestação, parto e nascimento, sintomas e diagnóstico de problemas após o nascimento, fenótipo e outras alterações no exame físico. Esse primeiro instrumento foi utilizado para maior compreensão das falas dos entrevistados. O segundo foi um roteiro de entrevista semiestruturada, que destacava questões relacionadas a gravidez, parto, nascimento e informações sobre o diagnóstico da microcefalia. Os dados foram coletados com o uso de gravador, com autorização prévia dos entrevistados e, posteriormente, foram transcritos.

A abordagem inicial aconteceu na sala de espera, no dia da consulta. Nessa ocasião, eram apresentados os objetivos da pesquisa e era realizado o convite para participação. A data e o local das entrevistas foram definidos de acordo com a conveniência dos participantes.

Foi utilizada análise de conteúdo, na modalidade temática. Os passos utilizados foram a pré-análise, com leitura flutuante das transcrições; a categorização do material, classificando os dados em busca das unidades temáticas; e a identificação dos núcleos de sentido - unidades de compreensão do texto 19,20. A inferência e a interpretação dos resultados foram feitas a partir de contribuições teóricas sobre comunicação de notícias difíceis que envolvem habilidades verbais e não verbais 21 .

A pesquisa foi aprovada pelo Comitê de Ética em Pesquisa com Seres Humanos do Hospital Universitário da Universidade Federal do Maranhão (HUUFMA), sob o parecer no 2.111.125, obedecendo à Resolução no 466/2012, do Conselho Nacional de Saúde. Os nomes dos participantes foram substituídos por nomes iniciados com a letra M para as mães, letra $\mathrm{P}$ para os pais e letra B para a bisavó.

\section{Resultados e discussão}

Foram realizadas vinte entrevistas, sendo três com o casal (pai e mãe), 16 com mães e uma com a bisavó, envolvendo 23 entrevistados.

As mães foram as principais cuidadoras das crianças. Culturalmente, tem cabido às mulheres o cuidado dos filhos, em particular dos que apresentam adoecimento ou alguma deficiência 22 . Diniz 23 afirma que essa situação exige das mulheres quase uma exclusividade e, por conseguinte, uma abdicação de outros compromissos da vida social, visto que a priorização é dada ao papel de ser mãe. Por outro lado, elas têm assumido também um perfil ativista ou militante, na luta pelos direitos de seus filhos. Essa identidade ativista parece constituir-se, em certo sentido, como libertadora. 
Em relação às características sociodemográficas, as mulheres tinham de 15 a 42 anos de idade, a maioria era casada, com Ensino Médio e Fundamental completos. Tinham como ocupação as atividades do lar, e havia grande variação quanto ao número de filhos (de 1 a 9). Quanto aos três pais, a idade variou de 26 a 29 anos. Dois eram casados e um vivia em união consensual. Dois tinham Ensino Médio completo e um cursou Fundamental completo. Apenas um deles estava desempregado, ao passo que os outros trabalhavam em empregos formais. A bisavó entrevistada tinha 72 anos, era aposentada e tinha Ensino Fundamental incompleto. Em relação aos municípios de residência, 12 entrevistados moravam no interior do estado.

Quanto às crianças, 12 eram do sexo feminino e oito do masculino, a idade variou de 11 meses a 2 anos e 2 meses, todas tinham fenótipo característico, predominando a desproporção craniofacial e a depressão biparietal. As comorbidades mais associadas à microcefalia foram epilepsia e visão subnormal. Quanto ao local de nascimento, três nasceram em maternidades da rede privada e 17 na rede pública. Foram 11 casos no Município de São Luís e o restante no interior do estado.

A notícia de que os filhos tinham microcefalia foi inesperada para 14 entrevistados. Os outros seis haviam ouvido falar sobre a epidemia na mídia e já conviviam com o medo da doença. Os responsáveis pelas crianças percorreram uma difícil jornada, desde o momento de suspeita até a definição do diagnóstico, marcada por omissões, notícias controversas, incompletas, erradas e/ou tardias, que serão discutidas abaixo.

Apesar de o pré-natal ter sido realizado em todos os casos e de apenas uma gestante não ter feito ultrassonografia gestacional (USG) - as demais realizaram de dois a oito exames -, apenas cinco casos de microcefalia foram confirmados durante a gravidez. Das 19 que fizeram USG, em seis casos houve relato de alguma alteração no exame: suspeita de microcefalia (dois casos), alterações não especificadas (dois casos), diagnóstico de trissomia do 18 (um caso) e hidrocefalia (um caso). Os outros oito casos receberam resultado de USG normal. Todos esses casos foram confirmados com microcefalia após o nascimento das crianças, alguns tardiamente.

Quanto ao momento do diagnóstico, além dos cinco que receberam a notícia durante o período gestacional, por meio da USG obstétrica, seis casos tomaram conhecimento da microcefalia ao nascer, um caso durante o trabalho de parto após realização de USG de emergência e os outros oito casos após o nascimento, variando de 11 dias a 9 meses.

O diagnóstico de microcefalia foi dado por médicos em 15 dos 20 casos. Nos outros três casos, a informação foi dada por uma enfermeira, pela sogra (que soube pelo médico) e por uma funcionária da Secretaria de Saúde. Os dois outros não receberam diagnóstico: um casal soube da microcefalia pela Declaração de Nascido Vivo (DNV) e outro associou o problema do filho a informações veiculadas na mídia.

As falas foram organizadas em três eixos temáticos que desvelam a forma como os entrevistados foram informados ou descobriram a doença do filho: omissão do diagnóstico, processo de comunicação do diagnóstico e antecipação de prognóstico.

\section{Omissão do diagnóstico}

Para oito entrevistados, houve omissão do diagnóstico durante o pré-natal (sete casos) e mesmo após o nascimento (um caso). O profissional percebia o problema, mas parecia não se sentir seguro para fazer a comunicação.

"Ele falou que tava tudo normal, de coração, de tudo... mas da cabeça ele nunca me dava resultado. Não sei se ele tinha era medo. (...) Eu disse para o meu esposo: 'Eu acho que tem alguma coisa errada, porque no primeiro ultrassom ele já não me entregou e na segunda ele me entregou, mas não entregou com a cabecinha dele lá” (Maria).

"O médico não falou que ele tava com a cabeça menor, ele só chegou pra mim e falou assim: 'Quando tu chegar na tua cidade, procura o teu médico, que tá fazendo teu pré-natal, porque teu bebê tá com o coração muito acelerado', ele falou assim pra mim né, ele não quis falar que a cabeça era menor que o normal" (Michele).

Nota-se nos relatos que as mães perceberam que havia algo errado com seus filhos, e era algo que poderia estar sendo encoberto pelos profissionais. Para essas mulheres, nas duas situações, o médico não quis falar. 
Essas experiências vividas pelos entrevistados, de omissão do diagnóstico por parte de alguns profissionais, são atitudes que Hennezel \& Leloup 24 denominam de "conspiração do silêncio" e/ou "mentira piedosa".

A "conspiração do silêncio" pode ser definida como uma tendência ou um acordo para manter em segredo uma situação incômoda, que se desenvolve na cultura da mentira e/ou da omissão. A "mentira piedosa" é o uso de informações com conteúdo não verdadeiro, quando se considera a verdade mais prejudicial que a mentira. Nessa situação, a pessoa pode sentir-se desinformada, incompreendida e enganada 24.

Esse padrão de comunicação pode estar associado a uma tradição da ética médica e ao paradigma hipocrático de não produzir ou evitar todo tipo de dor física ou moral ao paciente. O medo de que o conhecimento da doença leve ao agravamento do estado físico e emocional das pessoas contribui para que a comunicação do diagnóstico não seja realizada de forma esclarecedora. Leva, então, a uma comunicação caracterizada por omissões 25 .

Em um sentido mais amplo, o silêncio pode revelar as dificuldades do homem frente à dor e à possibilidade de morte, presentes na transmissão de uma notícia difícil. Esse é um processo quase sempre estressante, tanto para quem recebe quanto para quem emite a notícia 26 .

O profissional, antes de realizar a comunicação, pode sentir medo, ansiedade e incerteza das reações das pessoas que irão receber a notícia. Desta forma, para não ter de enfrentar possíveis reações ou mesmo suas próprias emoções, muitos acabam omitindo a informação, anunciando-a de forma negligente ou transferindo a responsabilidade para outros 14 , a exemplo do que foi relatado por três entrevistados.

"Quando eu cheguei no quarto, cheguei perguntando por ela. Não queriam me dizer... e aí foi que elas vieram [mãe e sogra] e me falaram que ela tinha nascido assim. Não recebi diagnóstico de médico” (Melissa).

"Aína ambulância, indo pra São Luís, foi que a secretaria de saúde de lá, disse que a minha filha era especial" (Márcia).

"Depois de três semanas, a enfermeira foi lá em casa, pegou o nascido vivo dele e colocou microcefalia, só colocou o nome e saiu" (Patrício).

Nas três situações acima, havia acontecido contato anterior com os médicos. Para essas duas mães e para esse pai, a comunicação do diagnóstico é atribuição desse profissional, que deveria ter dito o que já sabia ou desconfiava na ocasião. Em um desses casos, não houve comunicação, apenas o registro do diagnóstico de microcefalia na DNV, três semanas depois do nascimento da criança, sem qualquer explicação.

É esperado que a notícia seja anunciada pelo médico, que tem a responsabilidade legal acerca do diagnóstico e do tratamento da doença, embora a comunicação em saúde envolva diferentes áreas disciplinares. O trabalho interdisciplinar pode, inclusive, favorecer o apoio técnico e emocional de que as pessoas envolvidas precisam 27.

Nesta pesquisa, uma questão importante pode estar relacionada à falta de domínio sobre o universo da SCZ que, por ser um fenômeno recente e sobre o qual os próprios profissionais não tinham conhecimento, pode ter representado um desafio, levando a dúvidas sobre o que e quando comunicar e, ao mesmo tempo, sobre como reportar a incerteza 8 .

Os relatos dos entrevistados sobre as informações recebidas fazem parecer que, na época, os profissionais ainda sabiam pouco sobre o que ocorria com as crianças. Basicamente, quando comunicavam a notícia, diziam apenas que algo parecia estar diferente. Esses resultados também foram encontrados por Carneiro \& Fleisher 28.

As dificuldades dos profissionais em identificar, confirmar e comunicar o diagnóstico de microcefalia, especialmente na gestação, podem estar na gênese do diagnóstico tardio que ocorreu em oito casos.

Em quatro situações, as próprias mulheres, com o passar do tempo, perceberam que havia algo diferente com seus filhos. É o que ocorre nas falas a seguir.

"Quando ele viu o perímetro cefálico que era 29, ele não fechou o diagnóstico de microcefalia: 'Mãe, a gente vai passar sete meses medindo a cabecinha dele pra ver se tá desenvolvendo.' Eu disse que eu queria uma tomografia, que eu queria logo saber. Aí ele disse: 'Não, ele tá muito pequeno, eu não vou expor ele a radiação"' (Marisa). 
"A neuro, depois de 15 dias, me falou que não tinha como ser microcefalia porque ele tava com $33 \mathrm{~cm}$ de perímetro cefálico. Aí eu também fiquei despreocupada, eu relaxei e descartei a possibilidade. Eu só tive certeza quando ele já tava com sete meses, que eu vi que o meu filho não evoluía, não sentava, não engatinhava como outras crianças do mesmo período dele" (Mila).

Essas falas sugerem que havia dúvidas em relação às medidas do perímetro cefálico para o diagnóstico de microcefalia, ou por desconhecimento ou por falta de parâmetros bem definidos. Sabe-se que os parâmetros reconhecidos pelo Ministério da Saúde para o diagnóstico sofreram mais de uma alteração desde o início da epidemia ${ }^{2}$. Isso pode ter dificultado o diagnóstico precoce e pode ter levado ao atraso do início das investigações em muitos casos.

A triagem ultrassonográfica e as sorologias maternas no pré-natal deveriam detectar a maioria das malformações. Porém, ainda há um número relativamente grande de crianças que são diagnosticadas como portadoras de anomalias cerebrais apenas após o nascimento 24.

Nos casos de microcefalia fetal, mesmo com muitos estudos definindo o tamanho da cabeça como critério diagnóstico, ainda não se sabe qual a idade gestacional ideal para o diagnóstico. Também não se sabe quando e quais critérios podem ser aplicados para excluir definitivamente a microcefalia, principalmente em casos decorrentes de infecções congênitas 25 .

Assim, o diagnóstico de microcefalia fetal frequentemente é feito apenas no terceiro trimestre e, na suspeita ultrassonográfica, sugere-se complementação com ressonância magnética do feto para se certificar da malformação e de possíveis alterações associadas. Entretanto, nem sempre os serviços de saúde dispõem desse exame, que tem um acesso limitado 25.

Após o nascimento, o diagnóstico de microcefalia deve ser definido pela medida do perímetro cefálico, menor que dois desvios padrões abaixo da média para sexo e idade gestacional 26 .

Apesar desses padrões definidos, é importante considerar que as anomalias decorrentes das STORCH (sífilis, toxoplasmose, rubéola, citomegalovírus e herpes) e Zika têm característica progressiva, e as lesões podem surgir em qualquer momento da gravidez e, inclusive, de forma tardia, após o nascimento da criança, o que dificulta também o diagnóstico ao nascer 4.

Em um caso, durante a gestação, os pais receberam o diagnóstico de trissomia do 18, de forma equivocada, após realização de USG. Após o nascimento, foi constatado que era microcefalia e foi excluída a trissomia.

A dificuldade de definição do diagnóstico e o consequente atraso da comunicação da notícia, por um lado, e as frequentes informações da mídia, por outro, em alguns casos, a exemplo de Marcela, fizeram com que a microcefalia fosse percebida pelo casal e sua família, por meio de noticiários: " $a$ gente passou a descobrir que ele tinha microcefalia a partir dos jornais. A gente ficava naquela expectativa: 'Será se o nosso tem microcefalia?' Então, enfim, assim a gente viu que o surto tava grande em Pernambuco e nos jornais, tudo que falava mais era do surto de microcefalia, ai que a gente caiu na real" (Marcela).

Ficou evidente que um dos desafios para os profissionais de saúde foi a dificuldade em estabelecer o diagnóstico de forma precoce, com segurança, precisão e detalhamento. Sabe-se que quanto mais precoce for o diagnóstico, maior será o tempo que o casal terá para se preparar para o nascimento, como também para iniciar o tratamento e minimizar o impacto das alterações nas habilidades cognitivas e motoras 18 .

Diagnósticos tardios podem levar a maior dificuldade na aceitação do filho e a atraso do tratamento, inclusive podendo produzir impactos negativos no acompanhamento da criança.

Nesses casos de diagnóstico tardio, em geral, foram as mães que perceberam a doença. A partir do momento em que identificavam desenvolvimento diferente do esperado ou aumento da intensidade de sintomas, antes pouco expressivos, partiam em busca de ajuda e respostas.

\section{Processo de comunicação do diagnóstico}

Para 18 entrevistados, a comunicação do diagnóstico não atendeu às suas expectativas, ou porque não trouxe os esclarecimentos necessários para conscientização a respeito da realidade do estado de saúde de seu filho nem o direcionamento relativo ao que estava sendo anunciado, ou por falta de uma atitude mais empática, conforme observado nas falas a seguir. 
"O médico só disse que ela tinha nascido com uma deficiência, só vi o médico nesse momento, depois eu não vi mais. No outro dia, já me mandaram pra casa, sem me dar nenhuma instrução e eu que tinha que me virar em tudo do começo ao fim" (Moana).

"Ela [médica] nem explicou direito, só disse: 'Tem microcefalia', acabou e pronto" (Mila).

"Ele [médico] não explicou. Foi muito ignorante, não teve aquela paciência comigo. Eu não sabia nem o que era microcefalia, era algo novo" (Marcela).

Além de Marcela, outros entrevistados desconheciam até mesmo o significado da palavra microcefalia e, após o diagnóstico, relataram sensação de desamparo, destacando a pouca consistência das informações recebidas em relação ao diagnóstico do filho e, portanto, não souberam nortear suas atitudes.

A inexistência de informações, orientações e possíveis encaminhamentos faz com que a família permaneça com dúvidas quanto à real condição de saúde do filho, e fica insegura por não saber a quem recorrer 22 . Ser informado do diagnóstico e das condutas necessárias para o cuidado com a criança torna-se imprescindível para os pais 29.

Vale dizer que comunicar uma notícia não é simplesmente informar e retirar-se. Trata-se de um longo processo, desenvolvido em várias etapas, pois algumas informações terão de ser repetidas em outros momentos, considerando que as pessoas sob grave impacto emocional geralmente não assimilam bem o que é comunicado 30 .

O diagnóstico de malformação congênita pode trazer consequências para o casal ao longo da gestação e repercutir depois do nascimento da criança. É considerado um fator de risco para a saúde mental, principalmente da mulher. Nesse sentido, a comunicação do diagnóstico e a forma como é percebido e compreendido possuem papel central na ressignificação da experiência de gestar ou cuidar de um bebê malformado 13 .

Na comunicação do diagnóstico, cabe ao profissional de saúde dialogar de forma segura, oferecendo-se à escuta das dúvidas, e informar sobre o impacto que a nova condição acarretará na vida da criança e da família 22.

Diante da desinformação gerada pela inadequada comunicação do diagnóstico e da expressiva repercussão midiática dos casos de microcefalia pelo Zika vírus, no Brasil, a Internet foi uma fonte de informações encontrada na busca para conhecer mais sobre a microcefalia.

"A gente não sabia o que era. Aí foi que eu comecei a pesquisar no Google... começou a dizer que o surto era pela questão do Zika" (Márcia).

"Aí corri atrás! Fui na Internet. Vi que ela precisava de fisioterapia, terapia ocupacional essas coisas..." (Mel).

Se, por um lado, esses recursos de tecnologia da informação podem fazer com que as pessoas já não se sintam tão desprovidas de recursos para se apropriarem de explicações e terminologias médicas, por outro, é preciso cuidado com informações duvidosas e potencialmente enganosas que podem ser veiculadas na mídia 31,32 , como, por exemplo, a correlação da microcefalia com vacinas vencidas, sem qualquer fundamento, que ganhou a Internet e as redes sociais 8 .

As notícias difíceis não precisam estar associadas a desesperança. Em duas situações, os profissionais demonstraram habilidade no processo de comunicação, segundo o relato a seguir.

"Quando cheguei lá na doutora... eu costumo dizer que ela foi um anjo na nossa vida. Ela me disse quase tudo que a outra médica falou, só que ela me disse de uma maneira diferente: 'Olha, eu vou te explicar o que o seu filho tem,' com aquela voz maciazinha, né? Que parece que ela canta ao invés de falar. Ela: 'Olha, mãe, o seu filho tem microcefalia. O que é microcefalia?' Ela foi me explicar, mas ela me disse uma coisa, que me animou muito. Ela disse assim: 'Mãe, pra todo mundo que você falar o que seu filho tem, diga que ele pode ir além, que ele tem muita capacidade.' Então, eu costumo dizer que a microcefalia fechou todas as janelas e essa doutora... ela abriu, escancarou uma porta pra mim" (Marisa).

Fica evidente que os familiares reconhecem quando a mensagem emitida tem clareza e oferece suporte emocional. Pinheiro et al. 33 afirmam que uma das características mais apreciadas pelos familiares, além das explicações sobre a doença, é que o profissional demonstre preocupação e interesse. Os familiares, na ocasião da comunicação da notícia, desejam sentir-se apoiados, por meio de palavras de consolo e demonstração de afeto. 


\section{Antecipação de prognóstico}

Outra questão encontrada foi a antecipação de prognóstico desfavorável. Em geral, os profissionais não apontaram caminhos e não ofereceram alternativas como, por exemplo, estimulação precoce ou outras formas de tratamento e acompanhamento.

"Quando ele nasceu, eu queria ligar logo, né? Ele [médico] falou que não era pra mim ligar, que ele ia viver só três meses. Ele disse que ele não ia viver” (Maria).

"Aí ela jogou minha filha em cima da maca e disse: 'tai oh, não vai andar, não vai falar, não vai estudar, o cérebro dela está destruído, a parte responsável por olhar, se mover, está destruída, se talvez ela andar vai chegar aqui caxingando da perna, e ainda perguntou se eu tava de luto: você tá de luto né?"' (Mônica).

"Ela disse: 'Seu filho tem microcefalia, tem atrofiamento de membros e tem paralisia cerebral, pode te conformar porque ele vai ter várias crises de convulsões, ele não vai fazer nada que uma criança normal vai fazer" (Marisa).

O modo como se comunica o diagnóstico também é importante e afeta a maneira como as pessoas reagirão à notícia 29 . Os profissionais de saúde não podem esquecer que o nascimento de uma criança com deficiência provoca, nos pais, sentimentos de medo e incertezas 34 . Nesse momento, devem ser evitadas tanto falsas esperanças, como postura excessivamente realista ou pessimista quanto ao prognóstico da criança, enfatizando os aspectos limitantes da deficiência 35,36

No momento da notícia, com uma escuta cuidadosa, é possível mostrar as possibilidades de desenvolvimento, as possíveis formas de superação das dificuldades, os locais de orientação familiar, os recursos de estimulação precoce e os centros de referência para atendimento às crianças com deficiência, a partir da necessidade de cada família 37. A família, quando bem esclarecida, terá mais oportunidades de compreender a importância de sua ação para amenizar e melhorar o prognóstico de seu filho 35 . Isso pode contribuir para que pacientes e familiares possam melhor enfrentar os desafios do turbulento período de adaptação à doença 24,38 .

A falta de apoio, acolhimento e orientações na comunicação da microcefalia fez com que emergissem das falas dos familiares expectativas com relação à maneira como eles gostariam de ter recebido o diagnóstico.

"Não era pra ela ter dito isso. Como uma profissional da área, uma neuropediatra, sabendo o que isso poderia causar, ela não teria que já chegar assim de frente com a gente. Teria que trazer um psicólogo pra conversar, preparar a gente pra ela poder dar esse diagnóstico. E acho, também, que ainda não seja nem o caso ainda de falar isso pra gente... como a gente já tava abalado no interior sem ter nenhum suporte, pela parte dos profissionais de lá, que foram muito incompetentes com a gente, aí chega aqui e ela faz a mesma coisa que o de lá" (Patrício)

"Então, não tinha aquela coisa de dizer: 'Não, mãe, fique aqui, vamos conversar', preparar a gente primeiro" (Paulo).

Alguns pais revelaram, em suas falas, insatisfação pela forma como foram abordados, apontando a necessidade de uma prática profissional que possibilite a escuta de suas demandas, emoções e que tenha empatia. Além disso, é importante também avaliar se o familiar está pronto para ouvir a notícia, o quanto deseja saber, respeitando e acompanhando-lhe o ritmo.

De modo geral, os programas de graduação e pós-graduação em saúde não oferecem treinamento específico sobre a comunicação de notícias difíceis. Muitos profissionais de saúde referem não ter recebido capacitação, bem como poucas oportunidades de adquirir experiência pela observação da prática 14

A comunicação de notícias difíceis é uma tarefa complexa que requer habilidades, tanto no ato de comunicar como de saber responder às reações emocionais dos familiares, manejar o estresse criado pelas expectativas, trabalhar com a capacidade de decisão do casal e a participação de outros familiares, além de dar esperança quando a situação é sombria. Para executar essa tarefa, é importante que haja preparo e preocupação por parte dos profissionais 14 .

\section{Considerações finais}

Este estudo revelou as diferentes formas como os pais de crianças nascidas com microcefalia tomaram conhecimento da condição de seus filhos no pré-natal, no momento do nascimento ou no pós-parto. 
A comunicação da notícia não atendeu às expectativas dos pais na maioria dos casos, sendo às vezes omitida ou considerada inadequada e traumática, com informações controversas, erradas, incompletas e tardias, e nem sempre feita por um profissional de saúde.

As formas de comunicação do diagnóstico da microcefalia aos pais influenciaram nos modos de aceitação e enfrentamento da situação.

Por fim, os pais relataram ainda suas expectativas com relação à forma como gostariam de ter recebido a notícia sobre a condição de seus filhos, envolvendo acolhimento e, principalmente, orientações sobre estratégias e/ou caminhos para cuidar e lidar com a situação.

\section{Colaboradores}

P. S. Oliveira contribuiu com a concepção e desenho do trabalho, análise e interpretação de dados, elaboração e revisão crítica do artigo. Z. C. Lamy contribuiu com a concepção e desenho do trabalho, análise e interpretação de dados e revisou criticamente o artigo. C. N. M. Guimarães e C. B. Rodrigues contribuíram com a análise e interpretação de dados e revisaram criticamente do artigo. A. A. M. Silva, V. M. F. Simões e P. S. Sousa revisaram criticamente o artigo. Todos os autores são responsáveis por todos os aspectos relacionados ao trabalho.

\section{Informações adicionais}

ORCID: Poliana Soares de Oliveira (0000-00033596-0194); Zeni Carvalho Lamy (0000-00029332-0542); Carolina Nívea Moreira Guimarães (0000-0002-0489-1301); Camila Brito Rodrigues (0000-0002-1005-3267); Antonio Augusto Moura da Silva (0000-0003-4968-5138); Vanda Maria Ferreira Simões (0000-0001-8351-1348); Patrícia da Silva Sousa (0000-0002-0717-2388).

\section{Agradecimentos}

Agradecemos à Coordenação de Aperfeiçoamento de Pessoal de Nível Superior (Capes), à Fundação de Amparo à Pesquisa e ao Desenvolvimento Científico e Tecnológico do Maranhão (FAPEMA), ao Conselho Nacional de Desenvolvimento Científico e Tecnológico (CNPq), ao Departamento de Ciência e Tecnologia do Ministério da Saúde (DECIT), à Secretaria Estadual de Saúde do Maranhão e ao Centro de Reabilitação e ao Centro de Referência Estadual em Neurodesenvolvimento, Assistência e Reabilitação de Crianças (NINAR).

\section{Referências}

1. Moreira MCN, Nascimento M, Mendes CHF, Pinto M, Valongueiro S, Moreira MEL, et al. Emergency and permanence of the Zika virus epidemic: an agenda connecting research and policy. Cad Saúde Pública 2018; 34:e00075718.

2. Secretaria de Vigilância em Saúde, Ministério da Saúde. Protocolo de vigilância e resposta à ocorrência de microcefalia. Brasília: Ministério da Saúde; 2016.

3. Miranda-Filho DB, Martelli CMT, Ximenes RAA, Araújo TVB, Rocha MAW, Ramos RCF, et al. Initial description of the presumed congenital Zika syndrome. Am J Public Health 2016; 106:598-600.

4. Villar J, Giuliani F, Fenton TR, Ohuma EO, Ismail LC, Kennedy SH; et al. INTERGROWTH21 st very preterm size at birth reference charts. Lancet 2016; 387:844-5.

5. França GVA, Pedi VD, Garcia MHO, Carmo GMI, Leal MB, Garcia LP. Síndrome congênita associada à infecção pelo vírus zika em nascidos vivos no Brasil: descrição da distribuição dos casos notificados e confirmados em 2015-2016. Epidemiol Serv Saúde 2018; 27:e2017473.

6. Mackenzie JS, Drury P, Arthur RR, Ryan MJ, Grein T, Slattery R, et al. The global outbreak alert and response network. Glob Public Health 2014; 9:1023-39.

7. Moura da Silva AA, Ganz JS, Sousa PD, Doriqui MJ, Ribeiro MR, Branco MD, et al. Early growth and neurologic outcomes of infants with probable congenital Zika virus syndrome. Emerg Infect Dis 2016; 22:1953-6.

8. Aguiar R, Araujo IS. A mídia em meio às 'emergências' do vírus zika: questões para o campo da comunicação e saúde. RECIIS (Online) 2016; 10(1). https://www.reciis.icict.fio cruz.br. 
9. Scott RP, Quadros MT, Rodrigues AC, Lira LC, Matos SS, Meira F, et al. A epidemia de zika e as articulações das mães num campo tensionado entre feminismo, deficiência e cuidados. Cadernos de Gênero e Diversidade 2017; 3:73-92.

10. Oliveira MC, Sá SM. A experiência parental após o diagnóstico da microcefalia por zika vírus: um estudo de caso. Rev Pesqui Fisioter 2017; 7:64-70.

11. Dantas MSA, Collet N, Moura FM, Torquato IMB. Impacto do diagnóstico de paralisia cerebral para a família. Texto \& Contexto Enferm 2010; 19:229-37.

12. Gomes AG, Piccinini CA. Malformação no bebê e maternidade: aspectos teóricos e clínicos. Psicol Clín 2010; 22:15-38.

13. Cunha ACB, Pereira Junior JP, Caldeira CLV, Carneiro VMSP. Diagnóstico de malformações congênitas: impactos sobre a saúde mental de gestantes. Estud Psicol (Campinas) 2016; 33:601-11.

14. Luisado V, Fiamenghi-Jr GA, Carvalho SG, Assis Madeira EA, Blascovi-Assis SM. Experiências de médicos ao comunicarem o diagnóstico da deficiência de bebês aos pais. Ciênc Saúde (Porto Alegre) 2015; 8:121-8.

15. Prinds C, Hvidt NC, Mogensen O, Buus N. Making existential meaning in transition to motherhood: a scoping review. Midwifery 2014; 30:733-41.

16. Lemes LC, Barbosa MAM. Comunicando à mãe o nascimento do filho com deficiência. Acta Paul Enferm 2007; 20:441-5.

17. Sanches LAS, Fiamenghi Junior GA. Relatos maternos sobre o impacto do diagnóstico da deficiência dos filhos. Cad Saúde Colet (Rio J.) 2011; 19:366-74.

18. Ribeiro MFM, Porto CC, Vandenberghe L. Estresse parental em famílias de crianças com paralisia cerebral: revisão integrativa. Ciênc Saúde Colet 2013; 18:1705-15.

19. Bardin L. Análise de conteúdo. 7ạ Ed. Lisboa: Edições 70; 2011

20. Minayo MCS. O desafio do conhecimento: pesquisa qualitativa em saúde. São Paulo: Editora Hucitec; 2013.

21. Baile W, Buckman R, Lenzi R, Glober G, Beale E, Kudelka A. SPIKES: a six-step protocol for delivering bad news: application to the patient with cancer. Oncologist 2005; 5:302-11.

22. Cerqueira MMF, Alves RO, Aguiar MGG. Experiências vividas por mães de crianças com deficiência intelectual nos itinerários terapêuticos. Ciênc Saúde Colet 2016; 21:3223-32.

23. Diniz D. Zika: do sertão nordestino à ameaça global. Rio de Janeiro: Civilização Brasileira; 2016.
24. Hennezel M, Leloup J. A arte de morrer. Petrópolis: Editora Vozes; 2005.

25. Breitbart W. Retidão, integridade e cuidado: como viver frente à morte. Revista Brasileira de Cuidados Paliativos 2009; 3:5-15.

26. Geovanini F, Braz M. Conflitos éticos na comunicação de más notícias em oncologia. Rev Bioét 2013; 21:455-62.

27. Borges MDS, Freitas G, Gurgel W. A comunicação da má notícia na visão dos profissionais de saúde. Tempus (Brasília) 2012; 6:113-26.

28. Carneiro R, Fleischer SR. "Eu não esperava por isso. Foi um susto": conceber, gestar e parir em tempos de Zika à luz das mulheres de Recife, PE, Brasil. Interface (Botucatu) 2018; 22:709-19.

29. Saltz E, Juver J, organizadores. Cuidados paliativos em oncologia. Rio de Janeiro: Senac; 2008.

30. Kovacs MJ. Comunicação em cuidados paliativos. In: Pimenta CAM, Mota DDCF, Cruz DALM, organizadores. Dor e cuidados paliativos: enfermagem, medicina e psicologia. Barueri: Manole; 2006. p. 86-102.

31. Zago LF, Pimentel PR. Esquecimentos midiáticos: mãe-sozinha, pai-ausente, bebêmonstro e a epidemia de Zika na Folha de S. Paulo on-line. Passagens 2017; 8:152-72.

32. Coelho EQ, Coelho AQ, Cardoso JED. Informações médicas na internet afetam a relação médico-paciente? Rev Bioét 2013; 21:142-9.

33. Pinheiro EM, Balbino FS, Balieiro MMFG, De Domenico EBL, Avena MJ. Percepções da família do recém-nascido hospitalizado sobre a comunicação de más notícias. Rev Gaúch Enferm 2009; 30:77-84.

34. Silva NLP, Dessen MA. Crianças com síndrome de Down e suas interações familiares. Psicol Reflex Crít 2003; 28:242-9.

35. Milbrath VM, Soares DC, Amestoy SC, Cecagno D, Siqueira HCH. Mães vivenciando o diagnóstico da paralisia cerebral em seus filhos. Rev Gaúch Enferm 2009; 30:437-44.

36. Barbosa MAM, Chaud MN, Gomes MMF. A vivência da mãe com um filho deficiente na perspectiva fenomenológica. In: Barbosa $\mathrm{M}$, Ivo M, Nunes C, Zaleski E, Barbosa M, Pádua A, organizadores. Dimensões do processo de cuidar em enfermagem. Campo Grande: Universidade Federal de Mato Grosso do Sul; 2004. p. 161-81.

37. Maciel MRC. Portadores de deficiência: a questão da inclusão social. São Paulo Perspect 2000; 14:51-6.

38. Kubler-Ross E. Sobre a morte e o morrer. São Paulo: Livraria Martins Fontes Editora Ltda.; 1996. 


\section{Abstract}

This article aims to understand how parents of children with microcephaly received the diagnosis. This qualitative study was conducted at State Referral Center for Children's Neurodevelopment, Care, and Rehabilitation (NINAR) in São Luís, Maranhão State, Brazil, from April 2017 to February 2018. Participants in the study included parents or guardians of children with microcephaly. Data collection included structured and semi-structured interviews with 3 couples, 16 mothers, and 1 great-grandmother, totaling 20 interviews. The sample was defined by the saturation criterion, and content analysis was performed according to the thematic modality. Eighteen interviewees reported that the diagnosis had been disclosed to them inappropriately and traumatically, sometimes linked to a sense of "end of life" and dissociated from orientation on ways to cope with the situation and care for the child. The diagnosis of microcephaly was disclosed by physicians in 15 of the 20 cases. Three other cases were disclosed as follows: one by a nurse, one by the mother-in-law (who had learned of the diagnosis from the physician), and one by a health department employee. The other two did not receive the diagnosis: one couple learned of the microcephaly from the infant's Certificate of Life Birth and the other associated the child's problem with information broadcast on the media. Three thematic lines were analyzed: omission of the diagnosis; process of disclosure of the diagnosis; and anticipation of the prognosis. The ways diagnosis of microcephaly was disclosed to families influenced how they accepted and coped with the situation.

Communication; Family; Parents; Microcephaly; Zika Virus

\section{Resumen}

Este artículo tiene como objetivo comprender cómo los padres de niños con microcefalia recibieron la comunicación del diagnóstico. Se trata de un estudio cualitativo, realizado en el Centro de Referencia Estatal en Neurodesarrollo, Asistencia y Rehabilitación de Niños (NINAR), en São Luís, Maranhão, Brasil, durante el período de abril de 2017 a febrero de 2018. Participaron en el estudio los responsables de niños con microcefalia. Las técnicas de recogida de datos fueron entrevistas estructuradas y semiestructuradas con 3 parejas, 16 madres y 1 bisabuela, totalizando 20 entrevistas. La muestra se definió por el criterio de saturación y se realizó un análisis de contenido de modalidad temática. Para los 18 entrevistados, la forma de la comunicación fue considerada inadecuada y traumática, algunas veces vinculada al sentido de "fin de la vida" y disociada de orientaciones sobre las formas de enfrentar la situación y cuidar del hijo. El diagnóstico de microcefalia fue proporcionado por médicos en 15 de los 20 casos y en tres casos: por una enfermera, por la suegra (que lo supo por el médico) y por una funcionaria de la Secretaría de Salud. Los otros dos no recibieron diagnóstico: una pareja supo que era microcefalia por la declaración de nacido vivo (DNV) y otra asoció el problema del hijo con la información a través de los medios de comunicación. Fueron tres los ejes temáticos analizados: omisión del diagnóstico; proceso de comunicación del diagnóstico y anticipación de pronóstico. Las formas de comunicación del diagnóstico de la microcefalia a los familiares influenciaron en las formas de aceptación y de saber cómo enfrentarse a la situación.

Comunicación; Familia; Padres; Microcefalia; Virus Zika
Recebido em 03/Dez/2018

Versão final reapresentada em 23/Mai/2019

Aprovado em 06/Jun/2019 